\title{
Urdimento
}

Revista de Estudos em Artes Cênicas

E-ISSN: 2358.6958

\section{Corpos encarcerados: Socioeducação numa experiência com a dança em Cuiabá}

\author{
Elka Moura Victorino \\ Maria Thereza Oliveira Azevedo
}

\section{Para citar este artigo:}

VICTORINO, Elka Moura; AZEVEDO, Maria Thereza Oliveira. Corpos encarcerados: Socioeducação numa experiência com a dança em Cuiabá. Urdimento, Florianópolis, v. 3, n. 39, nov./dez. 2020.

DOI: http:/dx.doi.org/10.5965/14145731033920200123 
Corpos encarcerados:

Socioeducação numa experiência com a dança em Cuiabá

Elka Moura Victorino ${ }^{1}$

Maria Thereza Oliveira Azevedo²

\begin{abstract}
Resumo
A proposta deste artigo é o relato de uma experiência em dança com jovens internos no Centro de Atendimento Socioeducativo de Cuiabá (CASE-MT) e uma reflexão sobre as estratégias criadas para o enfrentamento de uma situação complexa e conflituosa. No espaço de encarceramento que tem em seu cerne a perspectiva coercitiva, como trabalhar o corpo na dança, com adolescentes encarcerados?
\end{abstract}

Palavras-chave: Socioeducação. Dança. Estratégias.

\title{
Imprisoned bodies:
}

Socio-education in an experience with dance in Cuiabá

\begin{abstract}
This article describes a dance workshop with young interns at the Centro de Atendimento Socioeducativo de Cuiabá (CASE-MT) and reflects on the strategies used to face a complex and conflicted situation. In the space of incarceration that has coercion at its core, how can one use the body in dance with incarcerated teenagers?
\end{abstract}

Keywords: Socio-education. Dance. Strategies.

\section{Cuerpos encarcelados: la socio educación en una experiencia con danza en Cuiabá}

\section{Resumen}

El propósito de este artículo es el relato de una experiencia de danza con jóvenes pasantes del Centro de Atendimiento Socioeducativo de Cuiabá (CASE-MT) y una reflexión sobre las estrategias creadas para enfrentar una situación compleja y conflictiva. En el espacio del encarcelamiento que tiene la perspectiva coercitiva en su núcleo, ¿cómo trabajar el cuerpo en danza con adolescentes encarcelados?

Palabras clave: Socio educación. Danza. Estrategias.

${ }^{1}$ Doutora em Estudos de Cultura Contemporânea pela UFMT (2019). Performer, bailarina. Analista do Sistema Socioeducativo da Secretaria de Segurança Pública do Estado de Mato Grosso. elkavictorino@hotmail.com

2 Doutora em Artes Cênicas pela USP. Professora no Programa de Pós Graduação em Estudos de Cultura Contemporânea na Universidade Federal de Mato Grosso (UFMT). maritheaz@gmail.com 
A dança, o teatro e todas as artes da cena que tem em sua base a exposição corporal, necessitam da confiança e da liberdade de expressão para acontecerem. Mas, no espaço de encarceramento que tem em seu cerne a perspectiva coercitiva, como trabalhar o corpo na dança, com adolescentes encarcerados?

Este artigo $^{3}$ propõe relatar algumas das experiências realizadas em Socioeducação e discutir os questionamentos que envolveram o trabalho de dança com os adolescentes em conflito com a lei, em regime de internação, no Centro socioeducativo de Cuiabá-MT (CASE-MT) Pomert. O envolvimento com a rede das medidas socioeducativas trouxe a necessidade de encontrar estratégias para trabalhar os corpos dos jovens na dança, observadas e descritas aqui.

Seria possível, então, traçar estratégias, construir ferramentas e criar propostas que constituíssem uma prática educacional pautada na relação entre o adestrado corpo bailarina e os corpos rebeldes, de jovens que cometeram atos infracionais? Uma ação complexa, uma articulação entre relações de estranhamentos e reconhecimentos, entre corpos, comportamentos, percepções e crenças. Estranhamento que se ampliou na medida em que fui aprimorando a observação de mim e dos outros, das condições do trabalho, dos paradoxos existentes nas ditas "medidas socioeducativas", desenhando, assim, uma forma de trabalho possível para os reclusos.

Nesse sentido, os conflitos iniciais direcionaram as práticas e permitiram a identificação da diferença entre a corporeidade de um bailarino, o conjunto de particularidades como a fisionomia, a expressão, as ações e as emoções e a corporeidade dos adolescentes, com suas vozes arrastadas na fala repleta de gírias, os braços e as pernas largadas no caminhar descomprometido, os ombros jogados para trás e o olhar desconfiado, padrões corporais comumente presentes entre eles. Uma organização neuromuscular muito diferente da que foi construída

\footnotetext{
Artigo escrito a partir da tese de doutorado: Do cárcere à cena: corpos atravessados na dança performativa Para menores sob a orientação da Profa. Dra. Maria Thereza Azevedo.

Nome fantasia dado ao Complexo de atendimento socioeducativo, composto pela delegacia e juizado da infância e juventude e unidades de acolhimento ao adolescente em conflito com a lei. Para as comunidades Ikpeng (Kabibe) é o tempo de preparação dos jovens indígenas, cerimônia que demora em torno de dezoito meses, na qual os jovens são preparados para o exercício da cidadania. (SEDUC-MT, 2011).
} 
num corpo alinhado e esticado pelo ballet clássico.

Tal padrão de comportamento dos adolescentes se apresentava como uma estratégia de sobrevivência na prisão, pois os jovens precisavam assumir uma postura de poder e quanto mais grave o ato infracional, o B.O., como eles dizem, maior o respeito conquistado. Durante os quase cinco anos de convivência com estes adolescentes, constatei que, quanto mais estigmatizados como delinquentes e marginais, mais intensas eram as características dos gestos que eles carregavam em seus corpos.

\section{Estratégia 1 - Envolvê-los no processo}

- "Fessora, a senhora precisa ser mais safa5pra trabalhar aqui".

Bastou apenas uma aula, um breve e tumultuado momento com os adolescentes em conflito com a lei, internos na Unidade de Internação Provisória Masculina ${ }^{6}$ (UIPM) do Centro de Atendimento Socioeducativo de Cuiabá-MT (CASEMT) para certificar-me de que deveria aprender com eles, ou seja, envolvê-los no processo.

Incluir os adolescentes no processo de estruturação das aulas, foi uma primeira estratégia utilizada para o êxito da implementação da dança. Para isso, foi elaborado um momento de acolhimento individual, específico da equipe de profissionais de educação física ao adolescente. Consistia em preenchimento de uma ficha de identificação, seguido de anamnese ${ }^{7}$, avaliação física e postural, e orientações para as atividades relacionadas às aulas de dança e educação física.

Após inúmeras inquietações vividas a partir de situações de conflitos, as atividades foram programadas e executadas de acordo com a disponibilidade dos recursos humanos e logística da unidade, buscando dar visibilidade e atribuir

\footnotetext{
${ }^{5}$ Esperta, capaz de escapar de problemas na gíria falada nas prisões.

${ }^{6}$ Unidade Socioeducativa onde os adolescentes ficam, no máximo, quarenta e cinco dias, aguardando a decisão do juizado sobre a medida a ser cumprida.

${ }^{7}$ Coleta de dados subjetivos sobre o indivíduo, pautado em seu próprio relato sobre suas condições de saúde.
} 
importância às expressões corporais e artísticas, enquanto linguagem, aproximamo-nos das proposições do Sistema Nacional de Atendimento Socioeducativo (SINASE), que propõe redimensionar o Estatuto da Criança e do Adolescente (ECA) e o hiato existente entre o fazer e o saber a respeito da Socioeducação.

Nas reuniões de orientação eram estabelecidos os acordos sobre comportamentos, uniformes, horários, relatório, entre outras normas básicas para uma boa evolução das aulas e manutenção do respeito e boa convivência. Desta forma, a partir da compreensão da história de cada jovem, da anamnese de sua condição de saúde, pude traçar, com a participação deles, metas para nossos encontros e, pactuada com eles, estabelecer normas e condutas para a prática de uma nova atividade na unidade, as aulas de dança. Traçar junto com os jovens, no momento da acolhida individual, as normas de conduta nas aulas, bem como inseri-los no processo de escolha dos estilos de movimentos e das músicas, tornou possível o desenvolvimento do trabalho em dança.

Os gestos e comportamentos dos adolescentes levantaram questionamentos e reflexões críticas capazes de viabilizar proposições de, como achar uma forma de trabalhar com eles. Pude observar, durante a execução dos exercícios, um estranho pudor ao se recusarem em alongarem-se com as nádegas voltadas para o outro. Seriampudores relacionadas a algum processo de violência sofrido, ou simplesmente um pensamento machista? De qualquer forma, a manifestação de seus sofrimentos, em parte, era codificada no comportamento ameaçador, agravado pela necessidade de marcar o território e por estarem num ambiente, até então desconhecido que eram as aulas de dança.

\section{Estratégia 2: quebrando um circulo vicioso}

Corró de cadeia, ou seja, novata e inexperiente por ser a primeira passagem no sistema das prisões, logo percebi que a prioridade, dentro da rotina da unidade,

8 Tipo de cela ou xadrez existente em delegacias de polícia, onde a pessoa permanece temporariamente detida, em razão de prisão em flagrante delito ou cumprimento de determinação judicial, até sua remoção definitiva para estabelecimento prisional. 
não seria a aula de dança. Antes, teria que disputar dia e horário com as outras atividades consideradas prioritárias para os adolescentes, como "futebol no campo" e o "banho de sol". Contudo, era necessário tempo conhecer melhor a rotina e os jovens, observar a singularidade de cada um e fazer uma acolhida9individual para coletar dados de saúde, posturais, capacidades físicas e interesses pessoais em relação ao esporte e dança. Para isso, uma segunda estratégia foi necessária: quebrar um ciclo vicioso que girava nos moldes de uma cultura de cadeia, pois, para a execução de uma rotina ideal, eu esbarrei em outra já estabelecida, sem objetivos e metas, indisciplinada e à mercê dos desejos apenas dos jovens. Era preciso transformar a rotina estabelecida para a implementação de outra rotina, com objetivos que iriam além de exaurir fisicamente aqueles jovens.

Andrea Cristina Scislesky (2010) relata que, uma das formas dos adolescentes manifestarem seu ressentimento e sua angústia é apresentando suas performances e narrativas de sofrimento. Complementa criticando os programas de atendimento socioeducativo que não atentam para os conflitos sociais, causadores de tal sofrimento e rebeldia. Se a medida continuar apenas na leitura estritamente normativa, patologizante e/ou judicial, para explicar o ato infracional, será muito difícil capturar o que está além do indivíduo que comete um crime. "Não se considerarão uma série de situações cotidianas que os jovens, sobretudo os pobres, estão experimentando e que podem nos revelar fraquezas institucionais e ambivalências da sociedade brasileira." (Scislesky, 2010, p.54).

A segunda estratégia incluía também, envolver toda a equipe de trabalho, para vencer a disputa com as outras atividades e implantar a aula de dança. De forma participativa, aos poucos, a equipe multiprofissional (técnicos e educadores) foi sendo inserida nas aulas e nos momentos festivos, produzindo os relatórios da participação dos adolescentes de forma integrada, dentro de uma ética profissional. As decisões quantos aos dias e horários para a prática, a logística para a retirada dos jovens da cela, objetivos a serem alcançados, entre outras, eram

${ }^{9}$ Procedimento padrão praticado, pela equipe técnica (assistente social e psicólogo (a)), para estabelecer o primeiro contato com o adolescente, colher o histórico e explicar as condutas e procedimentos que serão realizados no período de internação. 
tomadas em conjunto, equipe técnica, educadores e agentes socioeducadores, para garantir uma rotina que não gerasse hierarquia de saberes.A manutenção de uma rotina dentro de uma unidade socioeducativa é de fundamental importância para o andamento das ações, visto que a cada vinte e quatro horas ocorre a troca do grupo de agentes, e as tarefas devem ter continuidade, sem que ocorra discordâncias, principalmente perante os adolescentes. "Todos devem falar a mesma língua, para que o guri não fique fazendo jogo de conversas para conseguir o que quer". Essa era uma frase bastante repetida pelos servidores nas reuniões de equipe.

Para a realização das atividades de acolhida e as aulas de dança, foi preciso enquadrá-las na organização interna quanto aos horários, disponibilidade dos espaços físicos e dos agentes socioeducadores que iriam acompanhá-las. Além das atividades internas da Unidade, como escola, atendimento técnico e de saúde, refeições e cuidados com a higiene e com os quartos, visitas familiares e dos grupos religiosos, havia as atividades externas, como as audiências e depoimentos. Com isso, as aulas de dança eram vistas, por alguns, como prêmio para os adolescentes criminosos, e eles, como "não merecedores", deveriam ficar somente presos. Ouvi algumas vezes frases como estas: "Bandido não deve ter regalias"! "Tem que penar aqui dentro"! "Essa aula é coisa para bichinhanoiado, viadinho de merda”!

Para outros profissionais, porém, estas poderiam proporcionar aos jovens a estruturação de outra rede de pensamentos, potencializando os aspectos positivos da formação do caráter e suscitando neles, outras leituras sobre o envolvimento com o crime e os aspectos sociais envolvidos. Pensam na dança para preencher o tempo e espaço da medida de privação de liberdade como uma simples medida de segurança social.

É sabido que a afeição e o carinho na relação educando e educador, é vista no contexto freireano como metodologia de aproximação da educação e do mundo.[...]Penso que assumir seu afeto pelos jovens, e de certa forma desejar um futuro próspero para eles, solidifique ou potencialize a qualidade do trabalho das e dos funcionários. (Marques e Berselli, 2020, p.05). 


\section{Estratégia 3: sobrevivência no ambiente de cárcere}

As dificuldades para a execução do trabalho profissional assim como os conflitos vividos, ocorreram, primeiramente, pela própria característica do local, semelhante a uma mini cadeia, "cadeinha", como é apelidado pelos servidores. Dos corredores largos da estrutura arquitetônica de cores frias ecoavam vozes confusas e vocabulários desconhecidos. Gritos e conversas vinham de dentro das celas, ressoando entre as paredes altas dos muros ao redor:

-“A sra. mexe com esse negócio de dança de balé, né fessora”?

Tal pergunta, por parte de um menino interno, surpreendeu-me.

-"Como você sabe"?

Ele me respondeu:

-"Ahhhhh! Fácil de vê. A sra. anda toda expitchada, ${ }^{10}$ parecendo uma girafa!

A partir dessa fala percebi que, naquele ambiente de cárcere, confinada, tinha que traçar uma terceira estratégia: a de sobrevivência. Era preciso desenvolver uma capacidade peculiar de destrinchar o corpo do outro, seja lá quem (adolescente, técnicos, agentes), a fim de antecipar situações de perigo, possíveis rebeliões, castigos, ou até mesmo, mortes.

As normas de convivência e os comportamentos assumidos para garantir a sobrevivência nas prisões, construídos ao longo do convívio entre os cerceados de liberdade, se perpetuam ao longo do tempo, preservando muitas particularidades e semelhanças, como, por exemplo, a gírias, as hierarquias estabelecidas de acordo com os atos infracionais, as barganhas de serviços ou produtos, entre outras. As representações concretas originadas dessas relações podem ser observadas, por exemplo, nas práticas corporais adotadas por muitos jovens internos, que assumem uma postura corporal referente ao imaginário de "bandido", com ombros alargados e estufados, andar com o tronco jogado para

${ }^{10}$ No linguajar cuiabano quer dizer esticada, alongada. 
trás e com os pés arrastados e o olhar intimidador.

A dança aqui, mais do que ter objetivo de uma prática restaurativa precisava, antes, ser uma prática que ampliasse o diálogo com os jovens, estimulando-os a refletir sobre sua atual condição e propondo uma ou nova possibilidade de comunicação corporal. Uma comunicação capaz de destituir o padrão "corpo bandido" e promover um pensamento crítico em relação aos movimentos e cenas trabalhadas nas aulas, capaz de refletir sobre seus comportamentos num contexto mais amplo do cotidiano dos jovens.

Paulo Artur Malvasi (2011) descreve alguns comportamentos dos "menores marginalizados", em determinados locais, como o desenvolvimento de uma estratégia de sobrevivência, uma forma de adaptação aos valores sociais dominantes, um posicionamento diante do sistema sociopolítico e econômico de que participam. Desempenhar com desenvoltura o estilo "bandido" parece ser adequado no contexto "cadeia", pois se trata de um estilo não comum a todos do mundo do crime, o qual recebe a atenção de garotas e o respeito de garotos.

Existir significa em primeiro lugar mover-se em determinado espaço e tempo, transformar o meio graças à soma de gestos eficazes, escolher e atribuir significado e valor aos inúmeros estímulos do meio graças às atividades perceptivas, comunicar aos outros a palavra, assim como um repertório de gestos e mímicas, um conjunto de rituais corporais implicando a adesão dos outros. (Le Breton, 2007, p. 07).

O julgamento de que "bandido bom é bandido morto", ou preso, por parte de muitos com base nos atos infracionais praticados pelos jovens, leva a um padrão de comportamento displicente e letárgico no trabalho com a socioeducação. O linguajar criado para apelidar objetos, situações, ações e indivíduos, como “cagueta”, “júlia”, “X nove”, “cabuloso”, também exemplifica o padrão cultural característico do ambiente de cárcere.

Importante observar que os adolescentes que se encontram em conflito com a lei, segundo Sandra Pereira e Maria Fátima Sudbrack (2008), não encontram sua imagem no olhar social e a sequência de perdas e exclusões que eles passam, aumenta o medo em relação ao bem-estar social e à morte. Colocam-se ora na 
posição de vítimas, ora na de vitimizadores, temem e idolatram ao mesmo tempo os marginais, afrontando a ordem vigente e se rebelando contra a falta de direitos. "Tornam-se violentos para ganharem uma identidade entre os seus, para serem reconhecidos, combatendo o temor da própria morte" (Pereira; Sudbrack, 2008, p.153). Muitos deles são rejeitados pela família, pela escola, pelo mundo do trabalho e pelas instituições de um modo geral, e suas carências afetivas ou seus desvios de personalidade encontram-se relacionados com a vida que tiveram. Criam, em função disso, uma nova realidade, com seu próprio código, que corresponde à vida delinquente.

Categorias sociais, mas também modos de subjetivação, como loucura, vagabundos e crianças, passam a existir com o advento do biopoder, não se tratando de categorias naturais, mas produzidas socialmente, as quais são operacionalizadas a partir de uma relação com a norma, em uma lógica produtora de códigos que oficializam determinada categoria para a qual serão direcionadas certas ações e para as quais se tecerá determinado discurso. (Foucault, 2008, p. 229).

Mas um fato relevante destaca-se nas considerações de Marcel Mauss: segundo ele, as técnicas corporais são transmitidas por meio da educação. Elas são atos tradicionais e eficazes, e, segundo o autor, "é nisso que o homem se distingue, sobretudo, dos animais: pela transmissão de suas técnicas e muito provavelmente por sua transmissão oral" (Mauss, 1974, p. 217). Assim, a educação é o meio através do qual o homem aprende a trabalhar o corpo, transmitindo de geração em geração as técnicas, a arte e os meios dessa manipulação. Tudo isso ela faz através da linguagem. Por isso podemos pensar que cada sociedade desenvolve a sua pedagogia corporal. Esse processo é mais do que imitação pura e simples. Ele é cultural.

Com a intenção de alcançar os objetivos de uma exemplaridade na ação educativa, nas condições necessárias para a formação de um vínculo criativo, solidário e construtivo, favorável para a melhoria da qualidade da relação estabelecida entre educadores e adolescentes foi programado, então, na unidade, um circuito diferenciado de ação para as aulas. 


\section{Urdimento}

Figura 1 - Aula de dança na UIPM

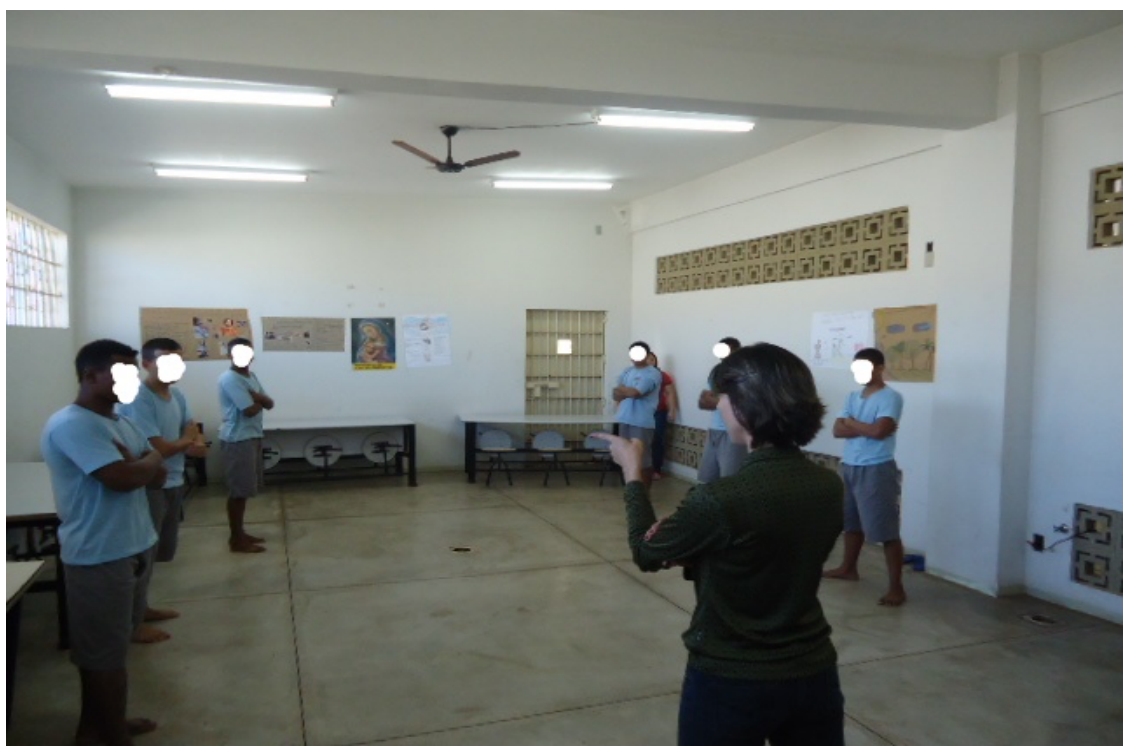

Acervo da UIPM, SEJUDH-MT, 2014

Vicente Concílio (2005) ao relatar as práticas teatrais em presídios traz, em uma das experiências, a complexidade das decisões coletivas que definem processo de construção do trabalho e do próprio grupo envolvido. Para o autor:

Tratava-se de um relacionamento diferente do habitual, para as presas, com o conceito de regras, que até então não se apresentavam a elas como um corpo orgânico, passível de alterações em fluxo dinâmico a fim de atender às necessidades do grupo, e que só teriam sentido se realmente fossem obedecidas não por medo de punição, mas por serem essenciais ao pleno funcionamento dos ensaios. (Concílio, 2005, p.154).

Concílio acrescenta que as reflexões no contexto das prisões adquirem vários sentidos nas esferas pedagógica, artística e social, no que diz respeito a um processo de criação livre, em um local de privação de liberdade. Corroborando com a fala do autor, a partir da compreensão da história de cada jovem, por meio de uma anamnese de sua condição de saúde. Foi possível estabelecer e pactuar com eles, metas para nossos encontros, bem como, as normas e condutas para a prática de uma nova atividade na unidade, a aula de dança. 


\section{Estratégia 4 - A dança como possibilidade}

Durante as aulas trabalhávamos improvisações de movimentos que iriam compor as coreografias para as festividades da unidade. Percebia que nas cenas compostas de ações mais teatralizadas, muitas vezes, os corpos jovens codificavam, em gestos, o estigma de irrecuperáveis e eternos suspeitos na cena do crime. Em suas representações coreografadas, traziam significados de diferentes realidades sociais, extrapolando a dimensão física dos gestos. De acordo com José Carlos Rodrigues (1986, p. 45), o corpo é sempre uma representação da sociedade, por isso não há processo exclusivamente biológico no comportamento humano. Rodrigues (1983, p. 121) afirma que:

[...]as práticas corporais são comportamentos nos quais os homens expressam, afirmam e reafirmam a sua solidariedade e a sua interdependência, expressas em sentimentos, valores e forças naturais que eles dominam e manipulam simbolicamente. [...]. São rituais sustentados por crenças míticas, pelos ritos, a fim de garantir, pela reafirmação periódica a ordem ideal do universo.

Buscava decodificar tais gestos, a fim de trazer recursos dos processos criativos capazes de romper com a vergonha e transformar a autoimagem deles. A montagem das cenas, o aprendizado dos passos, os exercícios para ganho de destreza e técnica, foram instrumentos norteadores desse sucesso pedagógico, pelo qual formamos um ambiente irradiador de culturas, de trocas de conhecimentos. A partir desses processos de compartilhamentos de criação, a aula de dança não era vista, apenas, como um instrumento de manutenção da ordem institucional, ou uma atividade para cansar os meninos para dormirem bem. Mas sim, um espaço para compartilhar objetivos e alcançá-los, de construção de projetos individuais e coletivos, e normas para que estes acontecessem.

Para alguns agentes socioeducadores, a aula de dança representava uma "atividade que dava disciplina para os moleques" (fala de um agente). A disciplina à qual se referiam não era aquela que se apoiava em qualquer aparelho repressivo, 
mas aquela que aparecia de forma difusa naquele campo social. Quem sabe, uma disciplina que conforme Foucault construía um dispositivo frequentemente artesanal, mas que orientava as formas físicas requisitadas, favorecendo o controle do espaço e do tempo, produzindo nos adolescentes, as marcas da obrigação de fidelidade que demonstravam suas vontades. Para muitos, a disciplina que interessava era aquela capaz de adestrar os corpos e docilizá-los como um batalhão de soldados a marchar, que não questiona e apenas executa a ordem recebida, dentro de uma "microfísica do poder." (Foucault, 2008).

Observando agora, com certa distância dos fatos, posso dizer que, provavelmente, o que mudou, no decorrer das aulas, foi a forma dos jovens verem seus corpos, suas possibilidades de movimentar, de criar gestos e interpretações, e de se posicionar no espaço, estruturando outras coerências em seus pensamentos, outras formas de estar no meio social e no mundo.

Figura 2 - Ensaio de dança com os adolescentes da UIPM

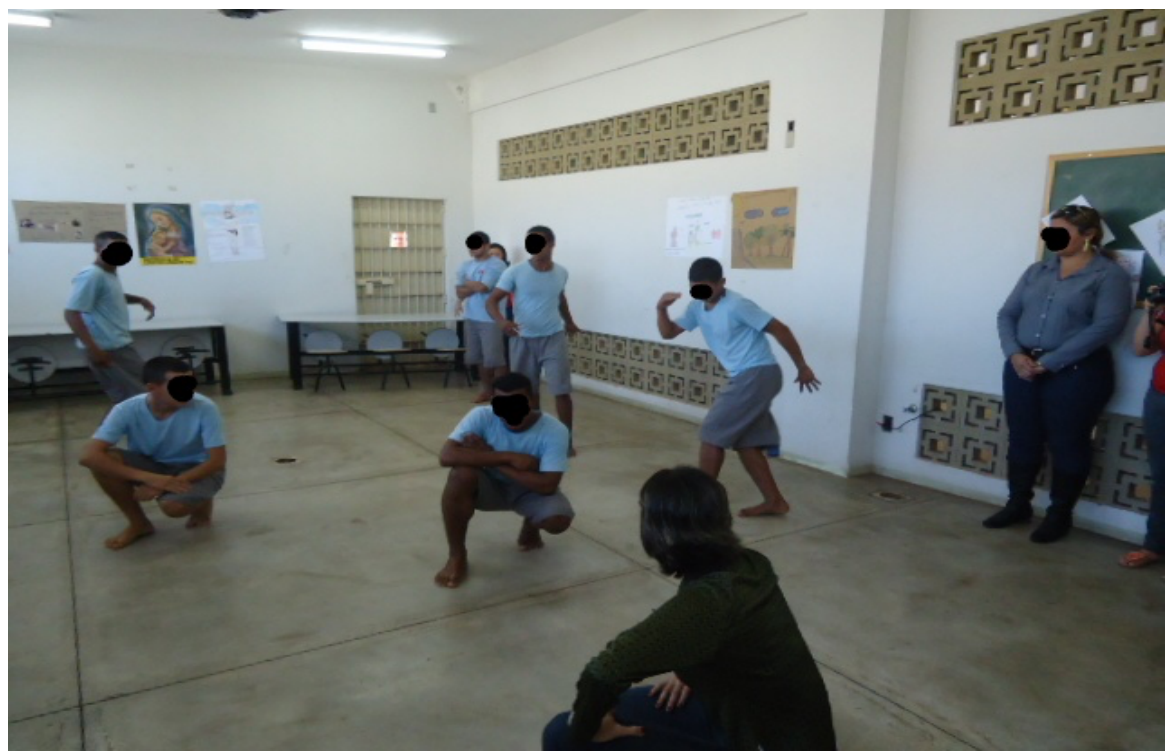

Acervo da UIPM-SEJUDH-MT, 2014

Em nossas histórias de vida, um aspecto nos identificava era a disciplinarização por nós sofrida pelo trabalho de adestramento proposto pelo sistema prisional, ou pelo ballet clássico. Tanto em um sistema, quanto no outro, a proposta é fragmentar o corpo a fim de que cada parte funcione em sua máxima 
eficiência, por meio de técnicas muito precisas que o docilizam transformando em um corpo produtivo e corpo útil, um corpo objeto nas diferentes práticas, conforme Michel Foucault (1999).

Não só os elementos do comportamento e da linguagem do corpo são objetos do controle, mas também, a organização, a economia e a eficácia dos movimentos. Para o controle, a única cerimônia que realmente importa é a cerimônia do exercício. Os métodos aplicados permitem o controle minucioso das operações do corpo por meio de coerções ininterruptas, sujeitando-o a constantes forças oriundas de uma relação entre utilidade e docilidade, as quais podem ser chamadas, conforme Foucault, de disciplinas. Para o autor a disciplina, na escala do controle, trabalha o corpo detalhadamente, mantendo-o- ao nível da mecânica, com movimentos, gestos atitude, rapidez, executados sob poder infinitesimal. Não se trata do cuidado em massa, como se fosse uma unidade indissociável, mas em uma disciplina que é uma "anatomia política do detalhe." (Foucault, 1987, p. 120).

A disciplina, de acordo com Foucault (1987) é diferente da domesticidade e da vassalagem, não se fundamenta numa relação de apropriação ou de submissão dos corpos, mas visa o aumento das habilidades deste, tornando-o cada vez mais obediente e consequentemente, mais útil.

Com esse entendimento sobre os dispositivos disciplinares não se pode pensar a dança para os adolescentes infratores como um projeto de disciplinarização centrado na própria exaltação do processo de ressocialização, como era vista e cobrada: "Essa aula de dança tem que dar disciplina para esses meninos, professora"!

Fica claro a necessidade do envolvimento de todos os participantes no contexto amplo do sistema, jovens, professores, equipe técnica, de saúde e agentes socioeducadores para se concretizar uma integração entre a dança e a proposta de reeducação social de jovens criminosos. Da mesma forma, Concílio (2005, p.157) diz que "a prática teatral em universos carcerários corre orisco de se perder na ingenuidade de propostas que não promovam o envolvimento crítico de seus participantes". 
Sendo assim, as estratégias práticas que foram estruturadas para possibilitar um trabalho consistente com a dança, estiveram inseparáveis de conceitos sobre os aspectos legais e educacionais das medidas de ressocialização, articulados com os saberes artísticos, sociais, econômicos e culturais.

É possível que, ao experimentar a dança, enquanto expressão corporal, codificação de gestos e criação de movimentos com os adolescentes privados de liberdade, e os desdobramentos em seus corpos, comportamentos e modos de viver por meio das estratégias utilizadas para seu ensino, possa ter proporcionado momentos de liberdade e confiança aos jovens presos.

\section{Referências}

BRASIL. Plano Nacional de Atendimento Socioeducativo: Diretrizes e eixos operativos para o SINASE. Brasília, DF: SDH/PR: CONANDA, 2013.

CONCÍLIO, Vicente. Teatro e prisão: dentro da cena e da cadeia. In: Sala Preta. São Paulo, v. 5, p. 151-158, 2005. Disponível em: < http://www.revistas.usp.br/salapreta/article/view/57273/60255 acesso em 10 out. 2020

ESTADO DE MATO GROSSO. Secretaria do Estado de Educação de Mato Grosso. Estruturação e Concretização de uma prática pedagógica nas unidades Socioeducativas do Estado de Mato Grosso. Diário Oficial da União. Cuiabá-MT. 2011. Disponível em:http://cos.seduc.mt.gov.br/upload/permanente/Arquivo/PROJETO\%20EDUCAR \%201\%20-\%20SOCIOEDUCATIVO77703069839599.pdf. Acesso em: 20 mar. 2018.

FOUCAULT, Michel. Vigiar e punir. nascimento da prisão. Petrópolis: Vozes, 1987.

FOUCAULT, Michel. História da sexualidade I: a vontade de saber. Rio de Janeiro: Graal, 1999.

LE BRETON, David. A sociologia do corpo. Petrópolis: Vozes, 2006.

MALVASI, P. A. Entre a Frieza, o Cálculo e a "Vida Loka": violência e sofrimento no trajeto de um adolescente em cumprimento de medida socioeducativa. Saúde Social, São Paulo: v. 20, n. 1, p. 156-170, 2011.

MARQUES,L. J. Berselli, M. Entre a cela e a cena: desafios de uma pedagogia teatral e carcerária. AMARgém, Uberlândia, v. 17, n. 1, jan-jun.2020. 
Disponível em: http://www.seer.ufu.br/index.php/amargem/article/view/56341. Acesso em: 10 out. 2020.

MAUSS, M. Ensaio sobre a dádiva. Forma e razão da troca nas sociedades arcaicas. In: Sociologia e Antropologia. v. II. São Paulo: Edusp, 1974.

PEREIRA, S. E. F. N. SUDBRACK, M. F. O. Drogadição e atos infracionais na voz do adolescente em conflito com a lei. Psicologia: Teoria e Pesquisavol.24, n.2.p. 151159, 2008.

RODRIGUES, J. C. O tabu do corpo. Rio de Janeiro: Achiamé, 1983.

SCISLESKI, A. (2010). Governando vidas matáveis: as relações entre a saúde e a justiça dirigidas a jovens em conflito com a lei. Tese de Doutorado. Curso de PósGraduação em Psicologia da Faculdade de Psicologia, Pontifícia Universidade Católica do Rio Grande do Sul, Porto Alegre 2010.

Recebido em: 15/10/2020

Aprovado em: 23/11/2020 